\title{
MATERIALS RESOURCE CENTER: Positions Available
}

\section{FLORIDA INTERNATIONAL UNIVERSITY}

\author{
FLORIDA INTERNATIONAL UNIVERSITY (FIU) \\ invites applications for several tenure track positions \\ beginning January, 2013,
}

in the Department of Mechanical and Materials Engineering

(Job ID No. 504342 and 504537).

FIU is a multi-campus public research university located in Miami, a vibrant, international city. FIU offers more than 180 baccalaureate, masters, professional, and doctoral degree programs to over 46,000 students. FIU has achieved Carnegie Research University status (with high research activity) and is one of the 25 largest universities in the nation. As one of South Florida's anchor institutions, FIU is worlds ahead in its local and global engagement and is committed to finding solutions to the most challenging problems of our times.

The Mechanical and Materials Engineering department has 20 faculty members who support its offerings of BS (ABET accredited), MS in ME and MSE, and PhD programs in ME and MSE. The department has close to 600 undergraduates and 80 graduate students. Research is supported by three research facilities, the Advanced Materials Engineering Research Institute (ameri.fiu.edu), the Motorola Nanofabrication Facility and the Center for Study of Materials at Extreme Conditions (cesmec.fiu. edu). The department's faculty research areas include:

- Thermal / fluid /HVAC / renewable energy / energy systems

- Mechanics/ Failure Analysis/ Vibration

- Robotics/mechatronics/ design/ manufacturing/electronic packaging

- Computational/ optimization/ multidisciplinary design methods

- Materials/ materials processing/ materials engineering

- Nanomaterials/ Nanotechnology/NEMS and MEMS devices

Duties of the successful candidates include teaching undergraduate and graduate courses in mechanical and materials engineering, mentoring students, developing an externally funded research program, and publishing scholarly work.

Qualifications: An earned doctoral degree in Mechanical Engineering, or materials engineering or a closely related engineering field is required prior to the start of the appointment. The successful candidates must have a demonstrated record of scholarly work and potential to establish a robust research program.

Job ID No. 504537: Special consideration for this position at all levels will be given to candidates with expertise in mechanical and physical metallurgy and experience in failure analysis, fatigue, fracture, dislocation mechanics, micro/nano-materials characterization, and nanotechnology. Candidates must have a commitment to teaching excellence and be qualified to teach courses in mechanical and materials science engineering, including materials in engineering, strength of materials, physical and mechanical metallurgy, physical properties of materials and composite materials.

Job ID No. 504342: Special consideration for this position at all levels will be given to candidates with expertise and experience in ceramics, nanoscale ceramic processing, nanotechnology and ceramic engineering. Candidates must have a commitment to teaching excellence and be qualified to teach courses in nanotechnology, nanomaterial properties, nanoscale modeling; ceramics microsystems and C-MEMS, ceramic processing, experience in nanoscale characterization including TEM and FIB applications.

Demonstrated excellent verbal and written communication skills are a prerequisite of all candidates for all the positions. FIU offers a competitive salary and benefits package, and an excellent work environment. Additional information is available at: http://careers.fiu.edu/.

Applications must include a letter of application, a curriculum vitae, a statement of research experience and plans, a statement of teaching experience and interests, and contact information for three references. Applications must be submitted on line at $\mathrm{http}: / /$ careers.fiu.edu/ only. Deadline has been reopened, but, to receive full consideration, applications must be received by November 15, 2012.

Applications are encouraged from members of under-represented minorities and women. FIU is a member of the State University System of Florida and is an Equal Opportunity,

Equal Access Affirmative Action Employer. www fiu edu/index.htm
TENURE-TRACK ASSISTANT

PROFESSOR POSITION

IN MATERIALS SCIENCE

The Department of Mechanical Engineering and Materials Science in the George R. Brown School of Engineering at Rice University, located in Houston, Texas, invites applications for a tenuretrack position in materials science at the Assistant Professor level, with an expected start date of July 1, 2013.

We seek an individual who has demonstrated excellence in one of the following areas in materials science: (1) Computational materials science from ab-initio to continuum methods with specific focus on: functional ceramics; electrochemistry; magnetic materials. (2) Advanced structural characterization techniques including but not limited to electron microscopy; X-ray techniques; scanning probe techniques. Preference will be given to the overall originality and promise of the candidate's work rather than to the sub-area of research. Exceptional candidates with other expertise will also be considered. A successful candidate will hold a Ph.D., or will have fulfilled the Ph.D. requirements by November 1 of the year employment commences, in a closely related discipline.

Applicants are expected to teach undergraduate and graduate courses. Successful applicants must also have a strong commitment to, and potential for excellence in, teaching, research, and service.

Applications should include a detailed curriculum vita that includes a list of publications, a brief statement of research and teaching interests, and the names of at least four references with references postal and email addresses, and telephone and fax information. Applications should be sent to msfacultysearch @ rice. edu or to the following address:

\section{Search Committee Chair -}

Materials Science Department of

Mechanical Engineering and

Materials Science

Rice University, MS 321

6100 Main Street

Houston, Texas 77005-1892

Candidates from under-represented groups, including women, are encouraged to apply. This position will be kept open until filled but priority will be given to applications received before December 1 , 2012. The position is at the Assistant Professor level but exceptional candidates at higher levels may apply. For information about the Department, visit our website at http://www.mems.rice.edu/.

Rice University is an Affirmative Action/Equal Opportunity Employer, committed to excellence through diversity. 


\section{MATERIALS RESOURCE CENTER: Positions Available}

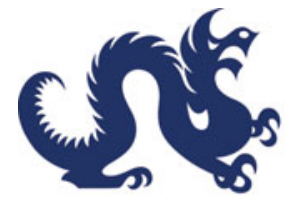

DREXEL UNIVERSITY Materials Science and Engineering

College of Engineering

FACULTY POSITION IN THE DEPARTMENT OF MATERIALS SCIENCE AND ENGINEERING AT DREXEL UNIVERSITY

The Department of Materials Science \& Engineering at Drexel University (www. mse.drexel.edu) is seeking applications for a tenured/tenure-track faculty position Of particular interest are candidates with a demonstrated record of excellence in original research in either:

1. soft and hybrid material design, synthesis, assembly, and function or

2. electrochemistry with emphasis in energy storage.

A Ph.D .in Materials Science and Engineering or a closely related field is preferred. The ideal applicant should also possess research interests in an emerging research area such as advanced energy technologies, biomedical materials and devices, or environmental sustainability, and be able to contribute to building interdisciplinary, integrated research program focused in their area of expertise.

Applicants should submit a cover letter; a full curriculum vitae; statements of research and teaching plans; and names and contact information of three references online at $\mathrm{http} / / / \mathrm{www}$.materials.drexel.edu/faculty/positions/.If afemale candidate is selected at the AssistantProfessorlevel, shewill beeligible forthe AnneStevens AssistantProfessorship. The position is available immediately and applications will be considered until the position is filled.

Drexel University is an Equal Opportunity Employer and encourages applications from qualified women and minorities.
I'VE SPECIALIZED FOR 33 YEARS

in the placement of Metallurgical, Materials, and Welding Engineers in the areas of R\&D, Q.C. Production, Sales \& Marketing, nationwide. My background as a Met. Eng. can help you! Salaries to \$190K. Fees paid by Co. Call/Send/E-mail Resume:

Michael Heineman, Meta-Find, Inc.; P.O. Box 610525, Bayside, NY, 11361; Phone: (212) 867-8100;

E-mail: mikeh@meta-findny.com; Web: www.meta-findny.com

\section{Don't Miss} An Issue!

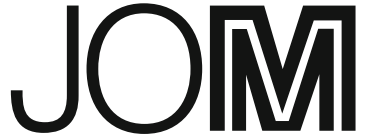

If you have not already done so, renew your TMS membership for 2013.

Visit: members.tms.org

This will ensure no interruption in receipt of your JOM subscription for 2013.
(Pfl

ÉCOLE POLYTECHNIQUE FÉDÉRALE DE LAUSANNE

\section{Faculty Position in Materials Science and Engineering} at the Ecole polytechnique fédérale de Lausanne (EPFL)
The School of Engineering of EPFL invites applications from candidates for a tenure-track assistant professor within its Institute of Materials. We seek exceptional individuals who will develop and drive a research program at the forefront of the discipline, who have a strong dedication to teaching at the undergraduate and graduate levels, and who will be proactive members of a vibrant Materials community.

Top-level applications covering all areas of materials science and engineering are invited with the following topics being of particular interest:

(i) electrochemistry as applied to the processing, microstructural tailoring or performance of materials,

(ii) the processing, microstructural tailoring, characterization or performance of materials having surface functionality, and

(iii) modeling and simulation as relevant to the processing, microstructural development and performance of materials.

Start-up resources and state-of-the-art research infrastructure will be available. Salaries and benefits are internationally competitive.

The EPFL, located in Lausanne, Switzerland, is a dynamically growing and well-funded institution fostering excellence and diversity. It has a highly international campus at an exceptionally attractive location boasting first-class infrastructure. As a technical university covering essentially the entire palette of engineering and science, EPFL offers a fertile environment for research cooperation between different disciplines. The EPFL environment is multi-lingual and multi-cultural, with English often serving as a common interface.

Applications should include a cover letter with a statement of motivation, curriculum vitae, list of publications and patents, concise statement of research and teaching interests, and the names and addresses of at least five referees. Applications must be uploaded in PDF format to the recruitment web site: imx-search13.epfl.ch

Formal evaluation of candidates will begin on 14 December 2012.

Enquiries may be addressed to:

Prof. Harm-Anton Klok

Search Chairman

e-mail: imx-search $@$ epfl.ch

For additional information on EPFL, please consult the web sites: www.epfl.ch, sti.epfl.ch and imx.epfl.ch.

EPFL is committed to increasing the diversity of its faculty, and strongly encourages women to apply. 


\section{MATERIALS RESOURCE CENTER: Positions Available}

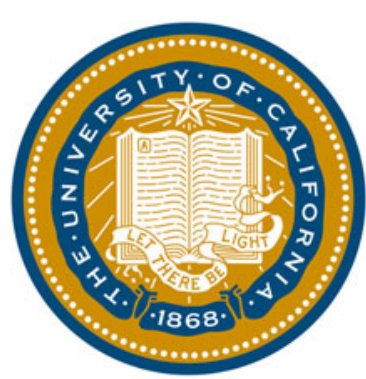

FACULTY POSITION

\section{Department of Materials Science and Engineering}

University of California, Berkeley

The Department Materials Science \& Engineering in the College of Engineering at the University of California, Berkeley, invites applications for a faculty position at the level of tenure-track assistant professor or associate professor with tenure. The expected start date is July 1,2013 . We seek an individual with demonstrated excellence in the broad area of electronic materials. Applicants must have a Ph.D. by June 2013 or equivalent and evidence of outstanding scholarship within a relevant discipline. The successful applicant will run a world-class electronic materials research program, offer undergraduate and graduate courses in materials science and engineering, and have a strong commitment to university service and diversity.

Applications are accepted online at https://aprecruit.berkeley.edu/apply/JPF00013 and should include a curriculum vitae with a list of publications, a description of research and teaching interests, three representative peer-reviewed (or in review) publications, and a list of at least three references. If you are unable to access the online application website, e-mail us at wanda @ berkeley.edu for the physical address to mail the application.

Formal review of applications will begin December 1, 2012. The closing date for applications is January 2, 2013.

The University of California is an equal opportunity affirmative action employer, committed to excellence through diversity. The college seeks candidates whose research, teaching, or service has prepared them to contribute to our commitment to diversity and inclusion in higher education. The college is also committed to addressing the family needs of faculty, including dual career couples and single

parents. For more information please go the CALcierge website at http://calcierge.berkeley.edu/

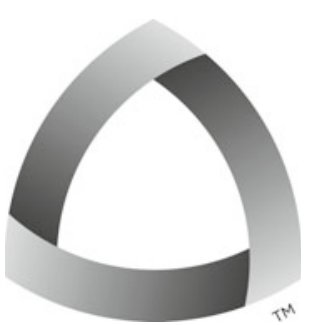

TENURE-TRACK POSITION

The George S. Ansell Department of Metallurgical and Materials Engineering invites applications for an anticipated tenure-track position in Physical Metallurgy at the level of Assistant Professor. The successful candidate will teach existing undergraduate and graduate level courses such as: foundry, welding metallurgy, advanced welding metallurgy, solidification, phase transformations, and transport in solids.

Applicants must possess a Ph.D., or equivalent terminal degree, in Metallurgical Engineering, Materials Science and Engineering, or related fields. The successful candidate will demonstrate the potential for successful teaching, scholarship, and service. The successful candidate will also demonstrate the potential for research excellence in the area of physical metallurgy preferably with an emphasis in the welding and joining of lightweight and/or high performance alloys. Experience in applications that result in weight reduction and energy savings using lightweight alloys is highly desirable. Applicants must possess excellent communication, organizational, and interpersonal skills.

For the complete job announcement and directions on how to apply, visit:http://inside.mines.edu/

HR-Academic-Faculty

\section{Tenure-Track/Tenured Faculty Positions in the Department of Materials Science and Engineering \\ The University of Texas at Arlington \\ Search Code: ENG101012MSE To apply, visit www.uta.edu/engineerapply.}

The College of Engineering at The University of Texas at Arlington is building areas of excellence that foster cross-disciplinary, cutting edge research. The Department of Materials Science and Engineering (MSE) is recruiting one or more outstanding faculty in these areas of excellence, including biomaterials and material/bio interfaces and/or advanced materials for nano/ micro electronics. Candidates with research specializations in other related materials areas will also be considered.

An earned doctorate degree in a core engineering or science discipline is required. Candidates must have demonstrated a commitment to quality teaching and scholarly research. Applicants in senior ranks are expected to have an excellent record of research, scholarship, funding and leadership, and a commitment to teaching and mentoring. A successful candidate is expected to develop sponsored programs that promote discovery, learning and engagement. Opportunities exist for collaborative research with UT Arlington research centers, programs, and local industry partners. The positions are interdisciplinary and the candidates must demonstrate an ability to work with faculty in science and engineering. Competitive salaries and research startup funds are available for these positions.

UT Arlington is a doctoral, research-extensive university with a current enrollment of over 33,000 students and is part of the University of Texas System. The University is located in Arlington, Texas, in the Dallas/FortWorth Metroplex, which is home to top clinical and teaching hospitals in the nation. It has the largest concentration of high-tech industry in the State of Texas and second in the nation after Silicon Valley. With more than 4,500 students and 23,000 alumni, the College of Engineering (uta.edu/engineering) is the fourth largest in Texas, and has ties to numerous high technology companies in North Texas. The College offers nine baccalaureate, 13 master's, and nine doctoral degree programs.

The MSE Department (uta.edu/mse) is primarily a graduate program that offers master's and doctorate degrees with excellent research facilities and a campus-wide, state-of-the-art Materials Characterization Center for Materials and Biology (ccmb.uta.edu). It has eight faculty members and more than 70 graduate students. Additional research opportunities exist at the Nanotechnology Research and Education Center (NanoFab, uta.edu/nano) and the UT Arlington Research Institute (UTARI, uta.edu/utari)

Review of applications will begin on November 1, 2012, and continue until January 15, 2013.

The successful candidate will be required to complete an Employment Eligibility Verification form and provide documents to verify identity and eligibility to work in the U.S. UT Arlington is an Affirmative Action/Equal Opportunity Employer. Women, minorities, veterans, and individuals with disabilities are encouraged to apply. The use of tobacco products is prohibited on UT Arlington properties. A criminal background check will be conducted on finalists. 


\section{MATERIALS RESOURCE CENTER: Positions Available}

\section{FACULTY POSITIONS \\ Materials Science and Engineering \\ University of Wisconsin - Madison}

The Department of Materials Science and Engineering at the University of Wisconsin-Madison seeks new faculty at the Assistant, Associate, and Full Professor levels. Distinguished candidates with outstanding records of achievement will be considered for the Y. Austin Chang Chair in Materials Science and Engineering.

Successful candidates will develop an internationally recognized research program, demonstrate leadership in attracting extramural funding, dedicate themselves to excellence and innovation in both undergraduate and graduate education, and provide service to the profession. We seek outstanding faculty pursuing research in the areas of advanced materials (including biomaterials, ceramics, metals, polymers), materials processing, and phase transformations.

UW-Madison offers world-class research opportunities, interdisciplinary collaborative research centers, and exceptional facilities for materials characterization, computation, and nanofabrication (www.engr.wisc.edu/mse/facultysearch). The University is committed to assisting candidates in achieving the highest levels of accomplishment.

Applicants for tenure-track positions must provide plans for teaching and research in materials science and engineering (each two pages maximum), a curriculum vitae, and three letters of reference. Candidates for tenured positions must provide curriculum vitae, teaching and research statements and contact information for five references. All materials should be sent electronically to mse.applications @ engr.wisc.edu. To ensure full consideration applications must be received by January 15, 2013.

Unless confidentiality is requested in writing, information regarding applicants must be released upon request. Finalists cannot be guaranteed confidentiality. UW-Madison is an equal opportunity/affirmative action employer.

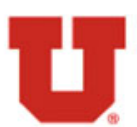

\section{THE UNIVERSITY OF UTAH \\ Department of Metallurgical Engineering}

Faculty Position - Tenure Track

The Department of Metallurgical Engineering at the University of Utah seeks to fill a tenure-track faculty position with an availability date of July 1,2013. Hiring at the assistant, associate or full professor level is anticipated. Applicants with teaching and research interests involving high-temperature chemical (pyrometallurgy) or physical processing of metals and advanced materials, hydrometallurgy, metallurgical thermochemistry including computational thermodynamics, and energy materials are encouraged to apply. The department has a rich tradition of excellence in all aspects of metallurgical engineering including mineral processing, chemical metallurgy, physical metallurgy, metallurgical processing, and manufacturing technologies.

The successful candidate should demonstrate a strong commitment to excellence in undergraduate and graduate education, and should also document the capability of establishing a strong externally funded research program. A doctoral degree in metallurgical engineering or an allied field is required. Salary and rank will be commensurate with qualifications and experience. Candidates who have demonstrated extraordinary accomplishments in research, teaching, and administrative service, who may be interested in serving as Department Chair and indicate the interest in their application letter, will be considered for the position. Demonstration of a strong commitment to and experience in undergraduate student recruitment is highly encouraged, especially for the position of Chair.

Review of applications will begin October 1,2012 and continue until the position is filled. Interested candidates are invited to submit a cover letter, a resume with a publication list, and the names, e-mail addresses, and telephone numbers of at least three professional references. The direct link to apply is: http://utah.peopleadmin.com/postings/17405.

The University of Utah is an Equal Opportunity/Affirmative Action employer and educator. Minorities, women, and persons with disabilities are strongly encouraged to apply. Veterans preference. Reasonable accommodations provided. For additional information: http://www.regulations. utah.edu/humanResources/5-106.html.

The University of Utah values candidates who have experience working in settings with students from diverse backgrounds, and possess a [strong or demonstrated] commitment to improving access to higher education for historically underrepresented students.

\section{Cut through the clutter...use the TMS Marketplace! Everything You Need for One-Stop Shopping...}

- Up to-date inventories from the leading materials suppliers

- Clutter-free searching for quick results

- Downloadable to your desktop for easy access

Visit www.tms.org and select the TMS Marketplace to access the most up-to-date information on vendors who support the metals and materials industries.

New Products and Services
Thermo-Calc Software Inc

Thermodynamic and Diffusion Modeling Software Ask about our new software releases! www.thermocalc.com Paul@thermocalc.com

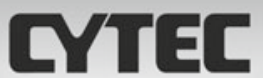

ALUMINA PROCESSING Telephone: +1 (973) 357-3193

US \& Canada Toll Free: (800) 652-6013 www.cytec.com

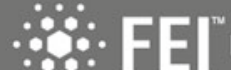
Explore. Discover. Resolve.

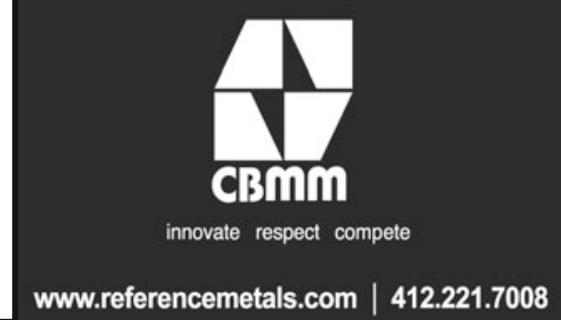

